\title{
Occurrence and fate of selected surfactants in seawater at the outfall of the Marseille urban sewerage system
}

\author{
F. Robert-Peillard · A. D. Syakti $\cdot$ B. Coulomb • \\ P. Doumenq $\cdot$ L. Malleret $\cdot$ L. Asia $\cdot$ \\ J.-L. Boudenne
}

Received: 5 March 2013/Revised: 21 December 2013/Accepted: 18 March 2014/Published online: 9 April 2014

(C) Islamic Azad University (IAU) 2014

\begin{abstract}
This paper describes an investigation of linear alkylbenzene sulfonates (LAS) and nonylphenol ethoxylates (NPEO) and their metabolites in the vicinity of the Marseille sewage outfall (wastewater treatment plant with a capacity of 1.860 million inhabitant equivalents, Northwestern Mediterranean, southeast of France). This analytical survey describes their occurrence in the subsurface and sea surface layers and investigates their possible fates in this marine environment. The results indicated the presence of LAS in both layers and up to $3 \mathrm{~km}$ from the discharge point, whereas the concentration of sulfophenyl carboxylic acids, which are the main metabolites of LAS, was only significant near the sewer outfall and in the surface layer. The NPEO were present only in minor quantities, especially near the discharge point, and no other selected metabolites were detected. The fate of the surfactants in question was then assessed by two types of experiments according to their potential means of degradation under natural conditions. Biodegradation assays were conducted according to a protocol defined by the United States Environmental Protection Agency
\end{abstract}

F. Robert-Peillard · B. Coulomb · J.-L. Boudenne ( $₫)$ Aix Marseille Université, CNRS, LCE FRE 3416, Equipe «Développements Métrologiques et Chimie des Milieux», 13331 Marseille, France

e-mail: jean-luc.boudenne@univ-amu.fr

\section{A. D. Syakti}

Fisheries and Marine Sciences Department-Jenderal Soedirman University, Kampus Perikanan Unsoed Karangwangkal,

Jl dr. Suparno, Purwokerto 53123, Indonesia

P. Doumenq · L. Malleret · L. Asia

Aix Marseille Université, CNRS, LCE FRE 3416, Equipe

«Micropolluants Organiques», Europôle de l'Arbois, Bâtiment

Villemin, BP 80, 13545 Aix-en-Provence, France
("Biodegradability in sea water, 835.3160"), with variations in the substrate input frequencies. Photodegradation experiments were carried out in a solar simulator reactor. These results demonstrated the low photodegradability and rapid primary biodegradation of LAS (with half-life times between 10.3 and 11.5 days) in the coastal area under study, although some LAS metabolites were more recalcitrant to biodegradation in this specific environment, which was also validated by linear alkylbenzene analysis in the two selected sediment stations.

Keywords Surfactants - LAS · NPEO - LAB - Seawater · Sediment $\cdot$ Biodegradation $\cdot$ Photodegradation

\section{Introduction}

Synthetic surfactants are organic compounds that are widely used in many domestic and industrial applications. They are used as ingredients not only in detergents, cosmetics, and personal care products but also in paints, paper and leather industries, pesticides, and more. The obvious consequences of this widespread application are the very high quantities of these compounds that are discharged into wastewater treatment facilities or directly in the environment (Mungray and Kumar 2009; Tubau et al. 2010).

Another consequence is the huge variety of surfactant molecules in use, although two main groups of molecules prevail; that is, the anionics and non-ionics, which represent more than $90 \%$ of the European consumption (LaraMartin et al. 2008a). Among these molecules, the linear alkylbenzene sulfonates (LAS) and alkylphenol polyethoxylates (APEO) are cause for major environmental concern. 
The LAS are anionic surfactants, and they are the most widely used synthetic surfactants in Europe, with an annual production of more than 400,000 tons in 2008 (CESIO, European Committee of Surfactants and their Organic Intermediates). Concerns about LAS arise from their bioaccumulation potential, their ability to enhance the apparent aqueous solubility of hydrophobic organic contaminants and their toxicity to bacteria, plants and animals (Hampel et al. 2001; Tan et al. 2010). Many studies have shown that LAS can be readily biodegraded under aerobic conditions, resulting in the formation of sulfophenyl carboxylic acids (SPC) via $\omega$-oxidation of the terminal carbon atom of the alkyl chain and successive $\beta$-oxidations (Boudenne et al. 2001; Swisher 1987). LAS and SPC concentrations in seawater vary greatly in the literature (from $\mu \mathrm{g}$ to $\mathrm{mg} \mathrm{L}^{-1}$ ), depending on the presence of treated or untreated wastewater discharges close to the sampling points (Lara-Martin et al. 2008b; Munoz et al. 2009).

With regards to non-ionic surfactants, APEOs have been banned in household cleaning products in northern Europe since 1995 but are still extensively used for industrial purposes. APEOs have a low biodegradability and form undesirable biodegradation products in wastewater treatment plants. The main types of APEO are nonylphenol polyethoxylates (NPEO), which can be transformed into various degradation products such as carboxylated metabolites (NPEC), mono- and diethoxylate derivatives (NP1E, NP2E) and nonylphenol (NP). These metabolites are considered to be endocrine-disrupting compounds that can potentially alter the normal hormonal function and physiological status of animals (Jobling et al. 1996). NP and NPEO have been detected in seawater at concentrations up to $20 \mu \mathrm{g} \mathrm{L}^{-1}$ (Bester et al. 2001; Gonzalez et al. 2004).

Specific analyses for LAS, NPEO and their metabolites are usually performed by solid phase extraction (SPE) followed by gas chromatography (GC) (Ding and Tzing 1998; Trehy et al. 1990) or liquid chromatography (LC) (Castillo et al. 2000; Di Corcia et al. 1994; Lara-Martin et al. 2010; Sarrazin et al. 1997). For some metabolites, GC requires a derivatization step prior to analysis, so LC analysis is often preferred when a global analytical method has to be devised for a general surfactant study. Various detection systems, such as UV (Sarrazin et al. 1997), mass spectrometry (MS) (Lara-Martin et al. 2010; Andreu and Pico 2004; Jahnke et al. 2004; Koh et al. 2008) and fluorescence (FL), have been coupled to the LC (Castillo et al. 2000; Di Corcia et al. 1994; Leon et al. 2000; Marcomini et al. 1987; Takada and Ogura 1992). Although it is less selective than MS, FL has been chosen for this study because it is the simplest detector for achieving high sensitivity for all the surfactants and metabolites of interest, as represented in Fig. 1.

Investigations of surfactant and metabolite concentrations and degradation in seawater are essential to understanding the impacts of these compounds in the marine environment. Little research has been published on these compounds in seawater, other than in the region of Cadiz (Atlantic Ocean) (Gonzalez-Mazo et al. 1997; Leon et al. 2004; Perales et al. 2003). Therefore, the aim of this study was to set up a global investigation of the most worrisome surfactants (LAS and NPE) in a Mediterranean environment to assess contaminant occurrence and fate. The goal of this work was thus to determine the amounts of LAS and APEO in the seawater subsurface, along with their metabolites. The surfactant concentrations were determined in samples that were taken from two transects previously selected according the prevailing currents and winds of the study area. Finally, biodegradation and photodegradation tests were conducted to predict the fate of the detected surfactants.

\section{Materials and methods}

\section{Materials and reagents}

LAS were purchased as a linear alkylbenzene sulfonic acid mixture from Alfa Aesar (Schiltigheim, France) and simply purified by recrystallization in $\mathrm{NaOH}(2 \mathrm{M})$. HPLC analysis provided the following alkyl chain distribution for LAS: $\mathrm{C}_{9}, 0.5 \% ; \mathrm{C}_{10}, 20.6 \% ; \mathrm{C}_{11}, 46.3 \% ; \mathrm{C}_{12}, 30.6 \%$; and $\mathrm{C}_{13}, 2.0 \%$. The $\mathrm{C}_{2}-\mathrm{C}_{8}$ SPCs were prepared by sulfonating commercial phenylcarboxylic acids according to a procedure described elsewhere (Sarrazin et al. 1997). A 4-nonylphenol of PESTANAL grade (NP), Igepal CO-210 (containing nonylphenol mono-, di- and triethoxylates) and Tergitol NP-9 (a nonylphenol ethoxylate mixture with an average number of nine ethoxy units) were purchased from Sigma-Aldrich (Saint-Quentin Fallavier, France). Nonylphenoxyacetic acid (NP1EC), nonylphenoxyethoxyacetic acid (NP2EC), nonylphenol monoethoxylate (NP1E) and nonylphenol diethoxylate (NP2E) were synthesized according to a procedure described by Diaz et al. (2002) from technical grade 4-nonylphenol. All synthesized compounds were characterized by mass spectrometry and purities were checked by HPLC.

Six mL ENVI-Carb cartridges were used for the solidphase extraction (SPE). Dichloromethane (DCM) of RPEACS grade was purchased from Carlo-Erba (Peypin, France), and HPLC grade tetrahydrofuran (THF) and trifluoroacetic acid (TFA) was sourced from Alfa Aesar (Schiltigheim, France). HPLC grade methanol $(\mathrm{MeOH})$ was obtained from Sigma-Aldrich (Saint-Quentin Fallavier, France).

All the solutions were prepared by dissolving or diluting appropriate amounts of reagents in ultra-high quality deionized water (Millipore, resistivity $>18 \mathrm{M} \Omega \mathrm{cm}$ ). 
Linear Alkylbenzene Sulfonates (Ex: C 11 LAS)

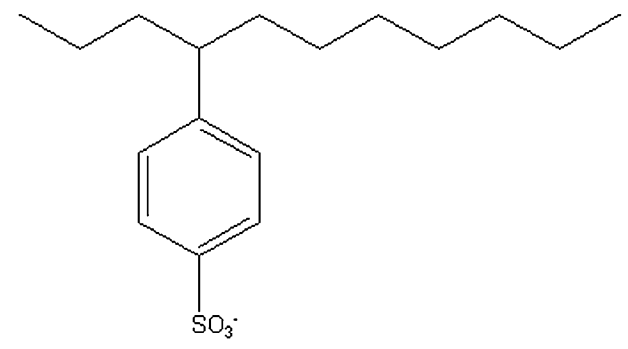

Sulfophenyl Carboxylates (Ex: $\left.\mathrm{C}_{4}-\mathrm{SPC}\right)$

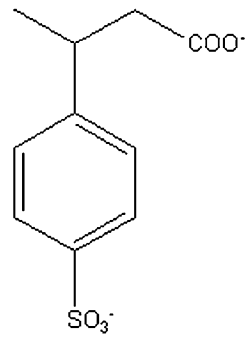

Fig. 1 Surfactant molecules under study

Study site: history and location

In the vicinity of the city of Marseille, the area known as Cortiou Creek (Fig. 2) is strongly influenced by sewage from Marseille and its suburbs, and is one of the most polluted places in the French Mediterranean. Of the whole of the Mediterranean Sea, this is also the place where the effects of sewage on both the environment and the biota are best known (for a review see Bellan et al. 1999). A daily output of about $250,000 \mathrm{~m}^{3}$ is discharged into the sea, the sewage flow being mainly carried westwards by the currents and prevailing winds. This transport process results in the dilution of the polluted waters, the deposition of contaminants on the sea floor and the establishment of a pollution gradient in the Cortiou Creek. The Marseille sewage was untreated until 1987 and has been treated only by a primary plant (chemically assisted sedimentation) till 2008. From this date, the wastewater treatment plant, one the largest in Europe (1,860,000 inhabitant-equivalent), uses a (primary) physico-chemical procedure including solid removal and chemically-assisted (flocculation/coagulation) sedimentation followed by a (secondary) biological treatment based on the Biostyr ${ }^{\circledR}$ system. The secondary-treated sewage effluent is released in the Cortiou Creek at the surface, with a daily average flow rate of $2.9 \mathrm{~m}^{3} \mathrm{~s}^{-1}$ (by dry weather).
Nonylphenyl Carboxylates $\left.\left(\mathrm{NP}_{\mathbf{n}} \mathrm{EC} ; \mathrm{NP}_{1} \mathrm{EC}, \mathrm{n}=0 ; \mathrm{NP}_{2} \mathrm{EC}, \mathrm{n}=1\right)\right)$

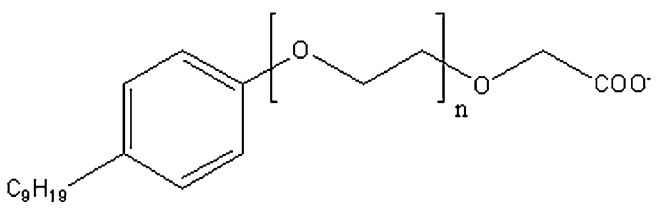

Nonylphenyl Polyethoxylates $\left(\mathrm{NP}_{\mathbf{n}} \mathrm{EO}, \mathbf{n}=1-20\right)$<smiles>CCCCCc1ccc(OCC)cc1</smiles>

Nonylphenol<smiles>CCCc1ccc(O)cc1</smiles>

Sample collection and preparation

The marine samples were collected at ten different points in the Bay of Marseille (Fig. 2), following two transects: (the discharge is close to sampling point number 4). Two different samples were taken at each sampling point, one representing the surface layer (0-5 $\mathrm{mm}$ depth) using a surface sampler (HydroBios, Kiel, Germany), and one at $2 \mathrm{~m}$ deep using a homemade Go-Flo-type sampling bottle. A $2 \%$ formaldehyde solution was added to each sample immediately after sampling for conservation purposes. The samples were taken back to the laboratory and kept in the dark at $4{ }^{\circ} \mathrm{C}$ until extraction (always less than $72 \mathrm{~h}$ after sampling) and subsequent analysis.

The surfactants were concentrated and extracted from marine samples using a classical SPE procedure described by Di Corcia et al. (1994). In brief, the extraction was performed with graphitized carbon black (GCB) cartridges (ENVI-Carb). Before extraction the samples were acidified to a $\mathrm{pH}$ of approximately 3 with $1 \mathrm{M} \mathrm{HCl}$ and vigorously shaken for $20 \mathrm{~min}$ to ensure adequate mixing and suspension of solid particles. After adequate preconditioning of the cartridges, $100 \mathrm{~mL}$ of water sample were passed through the GCB cartridges, followed by a washing step with ultrapure water and methanol. The desorption of nonionic surfactants was performed by passing $7 \mathrm{~mL}$ of $9 / 1$ $\mathrm{DCM} / \mathrm{MeOH}+25 \mathrm{mM}$ formic acid through the cartridges, 


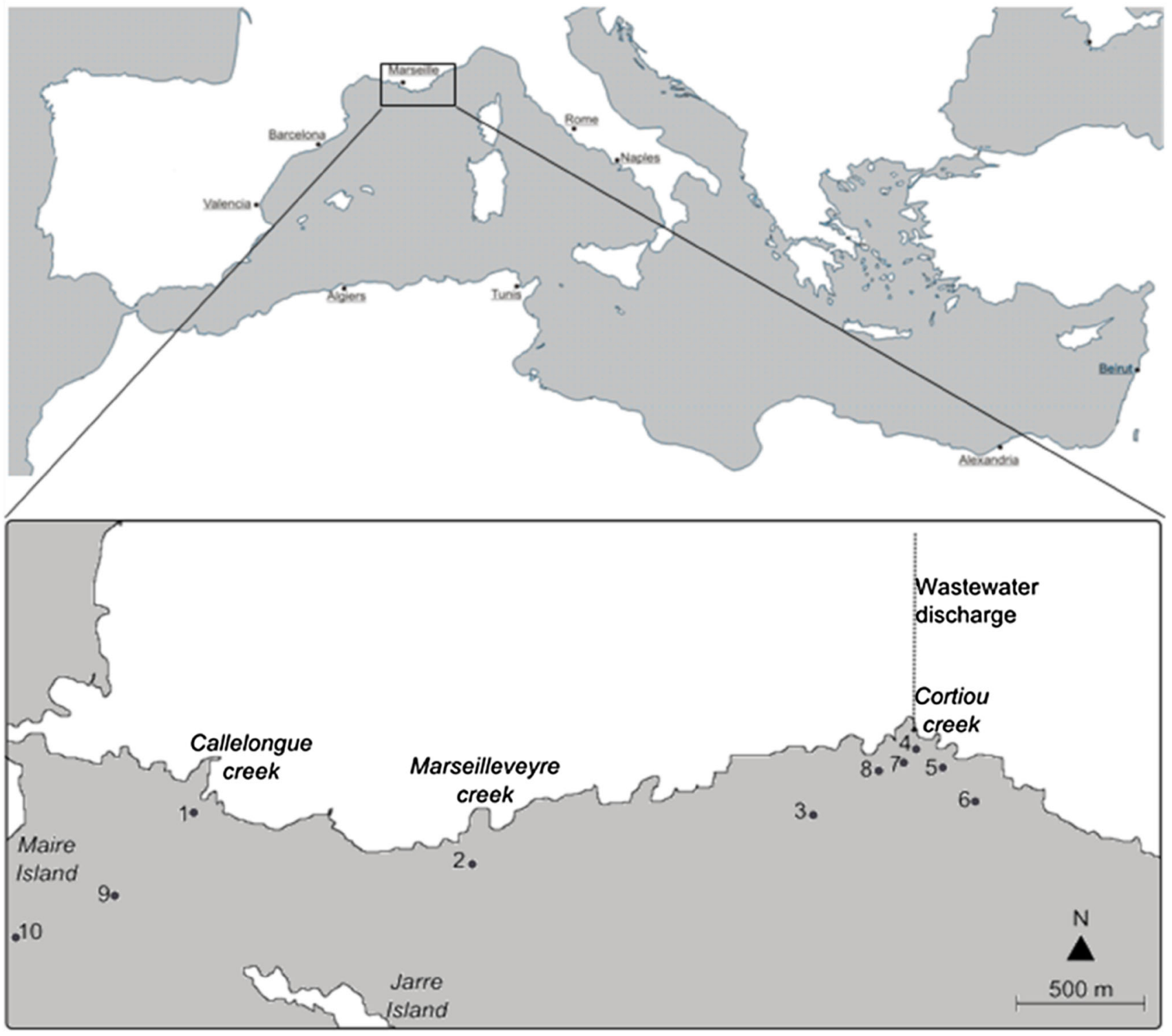

Fig. 2 Map of the Calanques of Marseille (France) sampling area

and the anionic surfactants were eluted with $7 \mathrm{~mL}$ of $9 / 1$ $\mathrm{DCM} / \mathrm{MeOH}+10 \mathrm{mM}$ tetramethylammonium hydroxide. This extract was neutralized with $6 \mu \mathrm{L}$ of $\mathrm{HCl}(12 \mathrm{M})$, and the eluates were evaporated under a gentle stream of nitrogen. Residues containing non-ionic and anionic surfactants were finally reconstituted in $1 \mathrm{~mL}$ of 55/45 THF/ Water and 50/50 $\mathrm{MeOH} /$ water (concentration factor $=100$ ), respectively, and $20 \mu \mathrm{L}$ of this final solution was injected into the LC system. All sample analyses were performed in duplicate according to this protocol.

LC analysis

The surfactants were analyzed with a VWR-Hitachi L-2130 high-performance liquid chromatograph equipped with a Dionex RF2000 fluorescence detector set at $\lambda_{\mathrm{ex}}=229 \mathrm{~nm} / \lambda_{\mathrm{em}}=289 \mathrm{~nm}$ for anionic surfactants and $\lambda_{\mathrm{ex}}=232 \mathrm{~nm} / \lambda_{\mathrm{em}}=301 \mathrm{~nm}$ for non-ionic surfactants. A $25 \mathrm{~cm} \times 4.6 \mathrm{~mm}$ i.d. column filled with $5-\mu \mathrm{m}$ particle $\mathrm{C}_{8}$ reverse-phase packing (Supelco Discovery) was used. The column was operated at ambient temperature with a $1 \mathrm{~mL} /$ min flow rate.

The following four eluents were prepared: eluent A, 85/15 TFA $0.1 \% / \mathrm{MeOH}$; eluent $\mathrm{B}, 15 / 85$ TFA $0.1 \% /$ $\mathrm{MeOH}$; eluent $\mathrm{C}, 23 / 77 \mathrm{H}_{2} \mathrm{O} / \mathrm{MeOH}+4 \mathrm{mM}$ ammonium acetate; and eluent D, 55/45 water/THF. The eluents were used in the analyses as follows:

- SPCs: elution gradient from $100 \% \mathrm{~A}$ to $100 \% \mathrm{~B}$ in $17 \mathrm{~min}$, then $100 \% \mathrm{~B}$ for $7 \mathrm{~min}$ (to remove LAS from the column). 
Fig. 3 Chromatograms of standard solutions for a SPC, b LAS, c NP-NPE, d NPEC (chromatographic conditions described in the experimental section)
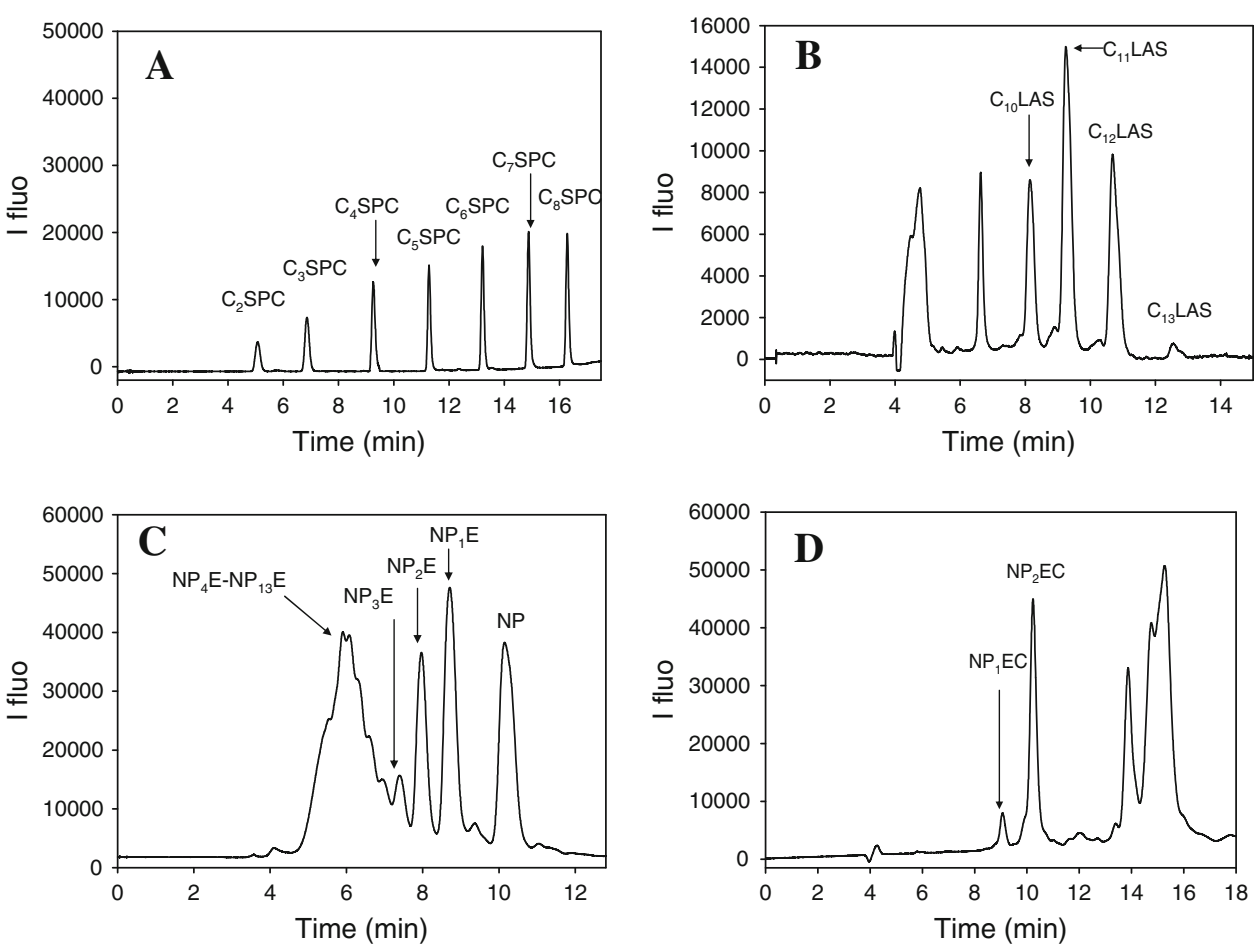

- LAS: $100 \%$ B for 15 min.

- NPEC: $100 \% \mathrm{C}$ for $20 \mathrm{~min}$.

- NP-NPE: $100 \%$ D for $13 \mathrm{~min}$.

GC quantification and recoveries

Quantification was performed with external standard solutions made from seawater that was free of contaminants and spiked with either SPC and LAS standards (anionic) or with $\mathrm{NP}$, Igepal, $\mathrm{NP}_{1} \mathrm{EC}, \mathrm{NP}_{2} \mathrm{EC}$ and Tergitol (non-ionic). The LAS calibration was based on the $\mathrm{C}_{11} \mathrm{LAS}$ peak (a common calibration for all LAS homologs), the $\mathrm{NP}_{1} \mathrm{E}$ and $\mathrm{NP}_{2} \mathrm{E}$ were calibrated with an $\mathrm{NP}_{1} \mathrm{E}$ peak, and the $\mathrm{NP}_{3} \mathrm{E}-\mathrm{NP}_{n} \mathrm{E}$ with $n \geq 3$ were calibrated with the global Tergitol peak (see chromatograms in Fig. 3).

Recoveries were calculated by triplicate assays with the $20 \mu \mathrm{g} \mathrm{L}^{-1}$ calibration solution to assess the efficiency of the extraction procedure. Detection limits (LOD) were calculated by using a signal-to-noise ratio of 3:1.

\section{Biodegradation experiments}

The biodegradation of LAS was assessed with natural seawater from the Mediterranean Sea. The seawater that was used in the biodegradation assays was sampled at the start of the experiment at sampling point number 10 (map in Fig. 2, $3.5 \mathrm{~km}$ from the wastewater discharge, $1,000 \mathrm{~m}$ from the coasts) at a depth of $2 \mathrm{~m}$. The physico-chemical parameters that were measured on-site were the temperature, $18.2{ }^{\circ} \mathrm{C}$; salinity, $36.3 \mathrm{~g} \mathrm{~L}^{-1}$; and $\mathrm{pH}$ 8.2.

Two assays were conducted according to the Office of Prevention, Pesticides and Toxic Substances (OPPTS) guideline 835.3160 "Biodegradability in sea water" (US.EPA 1998). The shake-flask method, which is used to verify that the study compounds are biodegradable in a marine environment, was employed with no added inoculum. According to the US.EPA protocol, the seawater was pretreated to remove coarse particles by filtering through a coarse paper filter. Assays were conducted in $1 \mathrm{~L}$ borosilicate glass bottles covered with aluminum foil to protect the samples from sunlight. One half liter of filtered seawater was added to each bottle and spiked to an initial concentration of $1 \mathrm{mg} \mathrm{L}^{-1}$ LAS. Four nutrient stock solutions were prepared. The first stock solution was composed of $8.5 \mathrm{~g} \mathrm{~L}^{-1} \mathrm{KH}_{2} \mathrm{PO}_{4}, 21.75 \mathrm{~g} \mathrm{~L}^{-1} \mathrm{~K}_{2} \mathrm{HPO}_{4}$, $26.6 \mathrm{~g} \mathrm{~L}^{-1} \mathrm{Na}_{2} \mathrm{HPO}_{4}$ and $0.5 \mathrm{~g} \mathrm{~L}^{-1} \mathrm{NH}_{4} \mathrm{Cl}$. The second, third and fourth stock solutions were composed of $27.5 \mathrm{~g} \mathrm{~L}^{-1} \mathrm{CaCl}_{2}, 22.5 \mathrm{~g} \mathrm{~L}^{-1} \mathrm{MgSO}_{4}$ and $0.15 \mathrm{~g} \mathrm{~L}^{-1}$ $\mathrm{FeCl}_{3}$, respectively.

The two experiments were carried out as follows:

- Experiment A: $0.5 \mathrm{~mL}$ of four nutrient stock solutions was added at the beginning of the experiment (procedure described in the USEPA guideline, which represents a large amount of added nutrients).

- Experiment B: $17 \mu \mathrm{L}$ of the four nutrient stock solutions were added every day in the morning for 
5 days per week (which represents regular and low additions of nutrients).

Each bottle was covered with an aluminum foil sheet and agitated at room temperature on a shaking table at $100 \mathrm{rpm}$. The room temperature was measured every day and was stable between 17 and $19{ }^{\circ} \mathrm{C}$ (average: $18{ }^{\circ} \mathrm{C}$ ).

The LAS and SPC concentrations were determined by HPLC (eluents described above) by direct injection of $1 \mathrm{~mL}$ seawater. Calibration curves were made by direct injection of spiked water samples. When analysis was not possible within 4 h, $2 \%$ formaldehyde was added to preserve the samples.

\section{Photodegradation experiments}

The photodegradation of LAS was assessed on a $5 \mathrm{mg} \mathrm{L}^{-1}$ LAS solution that was prepared in natural seawater (same sample as biodegradation experiments), which was sterilized by adding $2 \%$ formaldehyde. $50 \mathrm{~mL}$ of this solution was transferred into a $65 \mathrm{~mL}$ cylindrical glass reactor $\left(16 \mathrm{~cm}^{2}\right.$ surface for irradiation) equipped with a magnetic stirrer. The sample temperatures were maintained at $19 \pm 1{ }^{\circ} \mathrm{C}$ during the experiments by using continuous water cooling. Photolysis was conducted in a Luzchem Solar Simulator equipped with a $300 \mathrm{~W}$ xenon lamp (Luzchem Research Inc., Ottawa, Canada). The xenon lamp was set to generate a light intensity of 44,000 lux, which represents the annual average solar irradiation in southern France (Suri et al. 2007). The LAS and SPC were analyzed as described for the biodegradation experiments.

\section{Linear alkyl benzene analysis}

Freeze-dried sediments (of approximately $10 \mathrm{~g}$ ) were transferred to a pre-cleaned cellulose extraction thimble and extracted with a Soxhlet extractor apparatus for $16 \mathrm{~h}$ with a $200 \mathrm{ml}$ mixture of dichloromethane and hexane (1:1, V/V). Prior to the extraction, 1-phenlynonane was added to the samples as an internal standard (IS) for LAB quantification. All or part of the extractable organic matter (EOM) was dissolved in $n$-hexane and applied to a $50 \%$ alumina/ $50 \%$ silica $\left(8 \mathrm{~g}\right.$ of each, both deactivated with $5 \% \mathrm{H}_{2} \mathrm{O}$ ) chromatography column $(30 \times 1 \mathrm{~cm})$. The saturated fraction was eluted with $30 \mathrm{~mL}$ of $n$-hexane, resulting in a fraction that contained LAB. The LAB were separated by capillary gas chromatography (GC) with the following equipment: GC Autosystem XL Perkin Elmer chromatograph with on-column injection and a Perkin Elmer EliteXLB column $(30 \mathrm{~m} \times 0.25 \mathrm{~mm} \quad$ ID $\times 0.25 \mu \mathrm{m} \quad$ film thickness). Helium was used as the carrier gas at a constant rate of $1 \mathrm{~mL} \mathrm{~min}^{-1}$. The temperature was programmed from 70 to $285{ }^{\circ} \mathrm{C}\left(5^{\circ} \mathrm{C} \mathrm{min}{ }^{-1}\right)$ and then held for $30 \mathrm{~min}$.
The mass spectrometer was operated in electron impact ionization (EI) mode $(70 \mathrm{eV})$ and simultaneously scanned in both full scan and selected ion monitoring modes (SIFI mode). The identification of LAB relied on both the retention times and characteristic ions. The $91 \mathrm{~m} / \mathrm{z}$ ion was used for quantification, and the 105 and $119 \mathrm{~m} / \mathrm{z}$ ions were used for confirmation.

\section{Results and discussion}

\section{LC separations}

The separation of SPC and LAS has already been described in detail (Sarrazin et al. 1997; Leon et al. 2000; Marcomini et al. 1993) and was successfully performed with methanol and an aqueous phase containing trifluoroacetic acid (TFA) as a phase modifier (Fig. 3a, b).

NP and NPE analysis for various ethoxylate chain lengths is known to be problematic with conventional LCFL because all the compounds co-elute into a single broad peak with methanol or acetonitrile as the organic eluent. Mass spectrometry is therefore necessary to quantify these compounds when using these types of mobile phases. However, less conventional eluents such as tetrahydrofurane (THF) provides much better NPE compound separation because of its more specific interactions with the organic eluent (NPE and THF belong to the ether compounds) (Zgola-Grzeskowiak et al. 2009). An isocratic elution using a mixture of water and THF (55/45) enabled the separation of $\mathrm{NP}, \mathrm{NP}_{1} \mathrm{E}, \mathrm{NP}_{2} \mathrm{E}$ and other NPE compounds, the latter of which were identified as a broad peak (Fig. 3C).

Finally, $\mathrm{NP}_{1} \mathrm{EC}$ and $\mathrm{NP}_{2} \mathrm{EC}$ (carboxylated biotransformation products of NPE) were analyzed using a watermethanol mixture with ammonium acetate $(4 \mathrm{mM})$, which provided better separation and sensitivity, i.e., the same effects as those reported for LC-MS (Jahnke et al. 2004; Houde et al. 2002). The chromatograms of standard mixtures obtained under the reported experimental conditions are shown in Fig. 3.

\section{Limits of detection and recoveries}

The average recoveries are given in Table 1. Good to excellent recoveries were generally obtained except for $\mathrm{C}_{2} \mathrm{SPC}$ and NP. Previous studies using GCB cartridges for sewage effluent analysis exhibited good recoveries for these compounds (Di Corcia et al. 1994), so a possible explanation could be related to the higher salinity of seawater samples, which can affect the retention of some compounds in the SPE cartridges. 
Table 1 Average recoveries and standard deviations from triplicate determination of $20 \mu \mathrm{g} \mathrm{L}^{-1}$ standard solutions

\begin{tabular}{llll}
\hline Compound & Recovery $(\%)$ & Compound & Recovery (\%) \\
\hline $\mathrm{C}_{2}$ SPC & $58 \pm 4.5$ & $\mathrm{C}_{11} \mathrm{LAS}$ & $85 \pm 2$ \\
$\mathrm{C}_{3} \mathrm{SPC}$ & $94 \pm 4$ & $\mathrm{C}_{12} \mathrm{LAS}$ & $75 \pm 2.5$ \\
$\mathrm{C}_{4} \mathrm{SPC}$ & $90 \pm 2.5$ & $\mathrm{NP}_{1} \mathrm{EC}$ & $95 \pm 3.5$ \\
$\mathrm{C}_{5} \mathrm{SPC}$ & $85 \pm 4$ & $\mathrm{NP}_{2} \mathrm{EC}$ & $85 \pm 4$ \\
$\mathrm{C}_{6} \mathrm{SPC}$ & $91 \pm 5$ & $\mathrm{NP}$ & $42 \pm 6$ \\
$\mathrm{C}_{7} \mathrm{SPC}$ & $96 \pm 3.5$ & $\mathrm{NP}_{1} \mathrm{E}$ & $65 \pm 3$ \\
$\mathrm{C}_{8} \mathrm{SPC}$ & $95 \pm 4$ & $\mathrm{NP}_{2} \mathrm{E}$ & $77 \pm 3.5$ \\
$\mathrm{C}_{10} \mathrm{LAS}$ & $90 \pm 3.5$ & $\mathrm{NP}_{3-13} \mathrm{E}$ & $92 \pm 5$ \\
\hline
\end{tabular}

The detection limits were $0.2 \mu \mathrm{g} \mathrm{L}^{-1}$ for $\mathrm{C}_{2} \mathrm{SPC}$, $0.1 \mu \mathrm{g} \mathrm{L}^{-1}$ for other anionic surfactants and metabolites, $0.1 \mu \mathrm{g} \mathrm{L}^{-1}$ for NP and $0.05 \mu \mathrm{g} \mathrm{L}^{-1}$ for all other non-ionic compounds. These results represent the LOD for LAS and SPC two times better than the previously reported results (Leon et al. 2000) and on the same order for non-ionic surfactants (Nunez et al. 2007). These LOD are relevant to commonly observed surfactant concentrations in coastal waters, and they enable trace analysis of these compounds.

\section{Results of field sample analyses}

These results are depicted in the histograms shown in Fig. 4. Only the LAS results were present in both the surface layer and 2-m deep samples. Other compounds were indeed detected only at concentrations below or at the value of LOD at $2 \mathrm{~m}$ and were therefore not represented to present more readable results.

The LAS were the most frequently detected surfactants in our marine samples, and they were present in the whole samples and at concentrations up to $100 \mu \mathrm{g} \mathrm{L}^{-1}$ at the closest location to the wastewater discharge (Fig. 4a). LAS contamination was also elevated at distances as far as $3 \mathrm{~km}$ away from this discharge point (between 20 and $30 \mu \mathrm{g} \mathrm{L}^{-1}$ for surface samples at sampling points 1 and 9), clearly demonstrating the persistence and ease of transport of these organic contaminants. On average, LAS surface concentrations are three to four times higher than those at $2 \mathrm{~m}$ deep. Concentrations and differences between the surface and subsurface are on the same order as those described by Leon et al. (2000) for estuarine waters in the Bay of Cadiz in Spain. With regards to the LAS homolog distributions, $\mathrm{C}_{11}$ LAS and $\mathrm{C}_{12}$ LAS were the most significant ones (between 60 and $70 \%$ of the total LAS), followed by $\mathrm{C}_{13}$ LAS $(15-25 \%)$ and $\mathrm{C}_{10}$ LAS $(10-15 \%)$. This distribution was similar at all sampling points, regardless of the distance from the wastewater discharge area, which presumably indicates the transportation of discharged LAS mixtures before biodegradation takes place.
The SPC were only detected in surface layer samples close to the discharge point (Fig. 4B), with the highest value of $15 \mu \mathrm{g} \mathrm{L}^{-1}$ at sampling point number 4 (consistent with the above-mentioned study in the Bay of Cadiz). No more SPC could be identified at sampling point number 3 (600 $\mathrm{m}$ from sampling point number 4 ) and farther away. A dilution of SPC in the deepest seawater layers is likely to be responsible for this fast decrease in concentrations, SPC being less surface-active than LAS. The $\mathrm{C}_{4}-\mathrm{C}_{6}$ form accounted for more than $95 \%$ of the total SPC.

These concentration ranges for LAS and SPC are consistent with other studies, although some SPC could be measured at $2 \mathrm{~m}$ deep in the field study by Leon et al. (2000), which was contrary to our results. A faster dilution in our marine environment might be responsible for this discrepancy.

When compared to anionic surfactants, non-ionics (NPE) were present only in small amounts, even in the surface layer (maximum $\sim 2 \mu \mathrm{g} \mathrm{L}^{-1}$ ), and with low concentrations in the wastewater discharge area (Fig. 4c). This finding is consistent with the fact that NPEs have been banned in household cleaning products in France since 2005. The $\mathrm{NP}_{3-13}$ Es were the predominant NPE compounds, especially at sampling points 1-3, which have the most intense boat traffic and which exhibited the highest NPE contamination (possibly related to boat traffic or pollution from nearby creeks). The NP and NPEC were not detected in any samples at concentrations exceeding the LOD levels. The NPEC are usually detected when significant amounts of NPE enter the wastewater treatment system (Diaz et al. 2002; Petrovic et al. 2001), thereby supporting the idea that low NPE contamination is present in the wastewaters and seawater of the area surrounding Marseille compared to other areas in the world (Jonkers et al. 2005).

\section{Biodegradation study}

The results of the two experiments described above are shown in Fig. 5. With respect to the primary biodegradation of LAS, biodegradation was complete after 22 and 18 days for experiments A and B, respectively. The LAS half-life time was calculated by using first-order kinetics models, and the values were 11.5 days for experiment $\mathrm{A}$ and 10.3 days for experiment B. In both assays, a latency phase of approximately 8 days was observed, corresponding to an acclimation period of the bacteria that were present in the medium. With regards to LAS homolog distribution, there was a slightly preferential biodegradation for long-chain LAS homologs (with a faster decrease of $\mathrm{C}_{12}$ and $\mathrm{C}_{13}$ LAS peaks), as reported by other studies (Prats et al. 2006).

SPCs were detected starting on day 8 in the first two experiments, and they reached their maximum 
Fig. 4 Concentrations of LAS (a), SPC (b) and NPE (c) found in seawater samples in the

Calanques of Marseille area.

$S$ represents surface samples.

$P$ is for 2-m deep samples
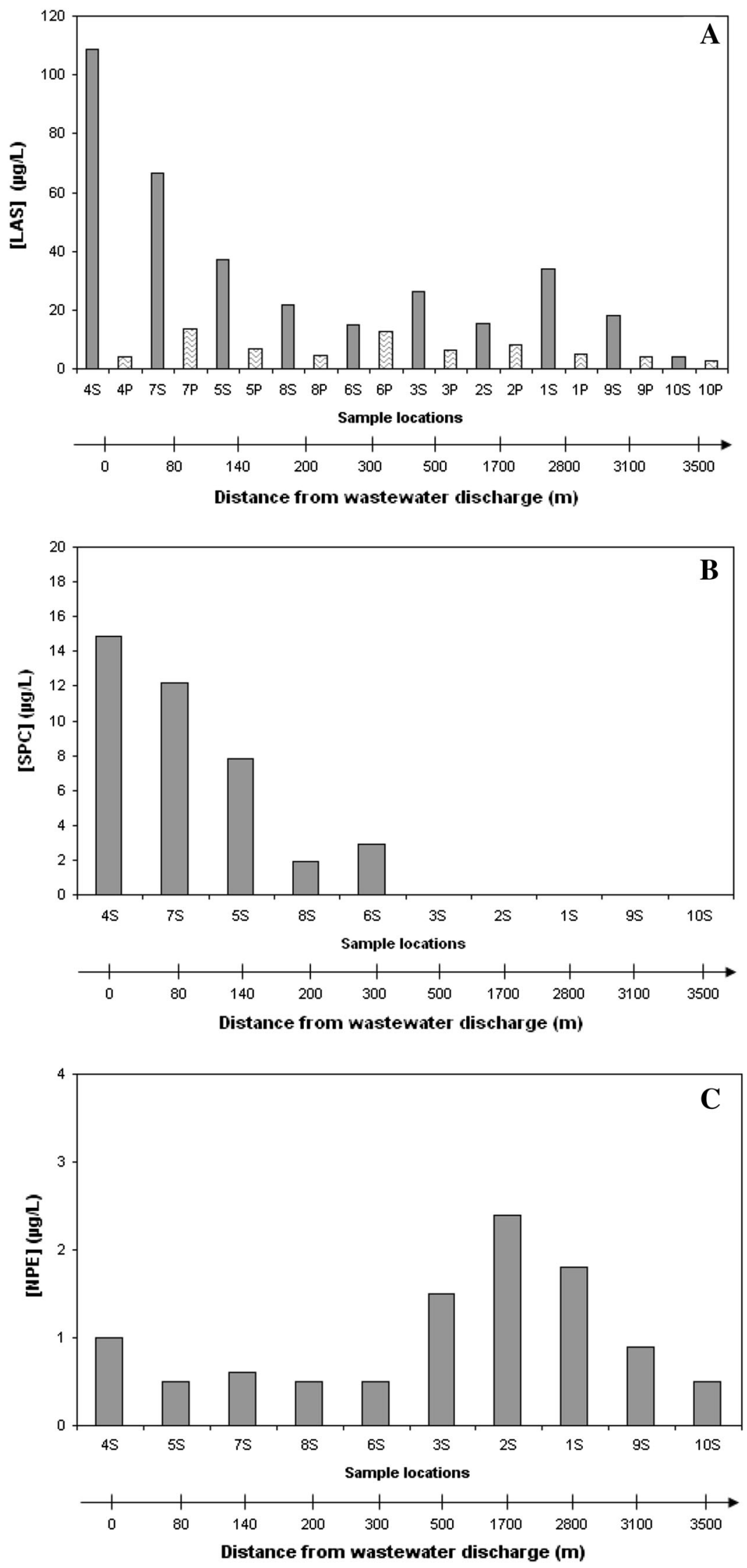

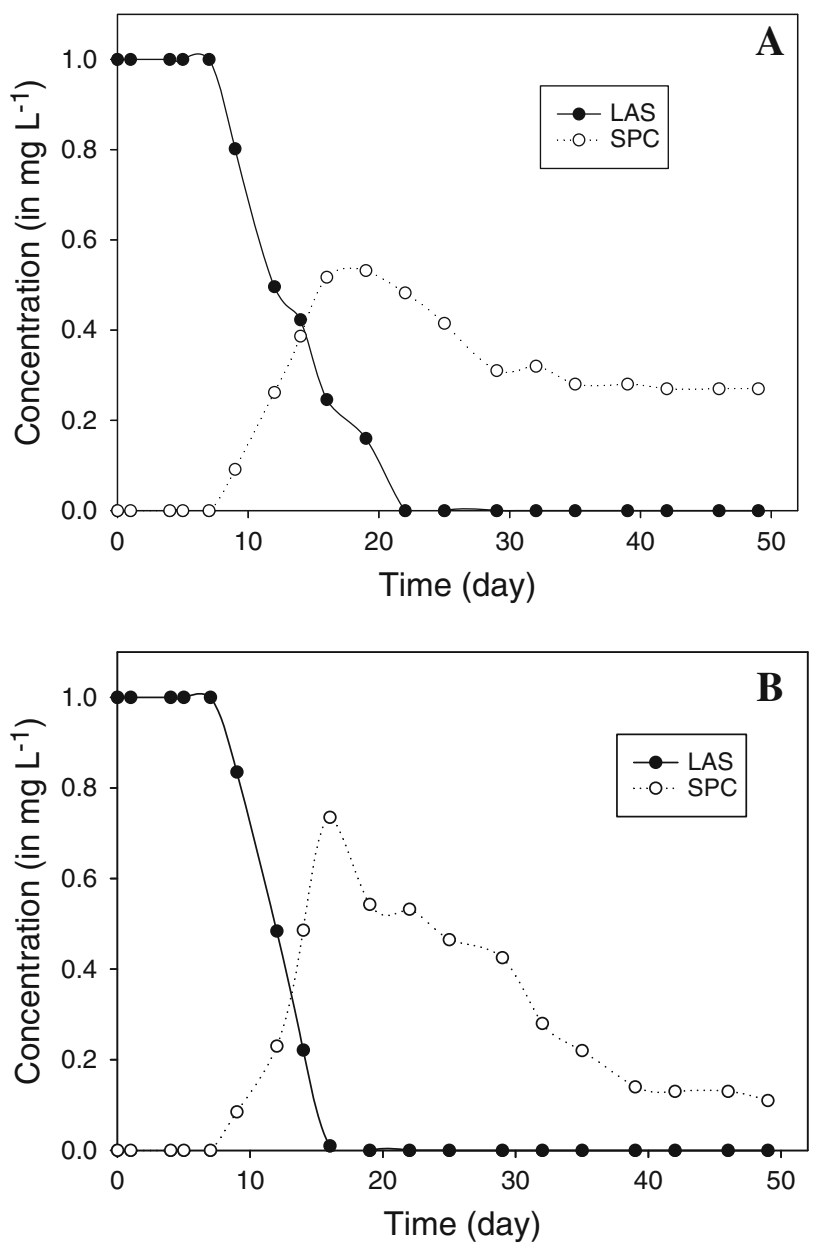

Fig. 5 Biodegradation results with a single and large nutrient additions at $t=0 ; \mathbf{b}$ regular and low nutrient additions

concentrations between days 18 and 20. In experiment A, the SPC degradation nearly stopped after day 30 , while it continued until the end of experiment B (day 48) in which only $10 \%$ remained in the medium. SPC can therefore not be considered to be totally biodegradable in our specific marine environment, especially when using reference protocol $\mathrm{A}$. The $\mathrm{C}_{2}-\mathrm{C}_{7} \mathrm{SPC}$ were detected throughout the time of the assays, with $\mathrm{C}_{4}, \mathrm{C}_{5}$ and $\mathrm{C}_{6}$ being the major variants at the beginning of the degradation. At the end of the experiments, $\mathrm{C}_{2}$ and $\mathrm{C}_{3}$ were the major metabolites.

In comparing the results of the two protocols, it can be noted that the biodegradation of anionic surfactants and their metabolites is faster and more complete when nutrients are added gradually (Protocol B). In this case, microorganism degradation activity was indeed still ongoing after 48 days, whereas with protocol A, which follows EPA guidelines, the large amount of nutrients that were added at the beginning were used inefficiently after a certain experimental duration (approximately 30 days). Protocol B thus seems better suited for reproducing real marine conditions in which the nutrients are brought into the seawater in relatively stable and small amounts. This protocol may thus be used to predict the fate of surfactants in coastal environments, which are subjected to constant sewage inputs.

These results were also compared with those obtained by Perales et al. (2003) who used seawater samples from the Bay of Cadiz (Atlantic Ocean), and where the experimental temperature was set at $20^{\circ} \mathrm{C}\left(18^{\circ} \mathrm{C}\right.$ in our study). Their experimental conditions were similar to those of protocol A. In their assay, the LAS degraded faster (with a half-life time of 6.2 days compared to our 11.5 days) and the SPC had totally disappeared within 42 days, showing a higher microbial degradation activity in their samples. The choice of seawater sampling in their study most likely explains the differences between their experiments and ours. Indeed, our samples were taken in an area that was far from the coast and likely with only natural marine bacteria, whereas the Perales group took their seawater samples much closer to the urban areas. It is therefore possible that their samples contained not only natural marine bacteria but also microorganisms originating from wastewater discharges. Our study seems more relevant for investigating genuine natural biodegradation in seawater.

\section{Photodegradation study}

LAS and SPC monitoring during the photodegradation assay showed that no SPC were formed during the 30 day assay, while the initial LAS concentration dropped by only $10 \%$ (Fig. 6). A control experiment conducted in the same way but with no light exposure exhibited the same drop, which was likely due to the process of LAS adsorption to the walls of the glass vial. From these results, it can be concluded that LAS are not photodegradable under the annual average solar irradiation conditions in southern France. Another experiment was conducted for 10 days with a simulated solar light of higher irradiance $(62,000$ Lux, or the annual maximal solar irradiation in July) and gave the same results, supporting the idea that biodegradation is the only (or most significant) process that can degrade LAS in the Mediterranean Sea environment. To the best of our knowledge, this concept had not been demonstrated in our specific environment with the high irradiance values of the summer period because irradiation light intensity is often not reported in other studies that address photodegradation with simulated solar light (Fernandez et al. 2004).

Linear alkyl benzenes (LAB)

During the industrial sulfonation processes for LAS synthesis, Gledhill et al. (1991) reported that $1-3 \%$ of LAB remain unreacted. Thus, $\mathrm{LAB}$ are considered to be tracer 


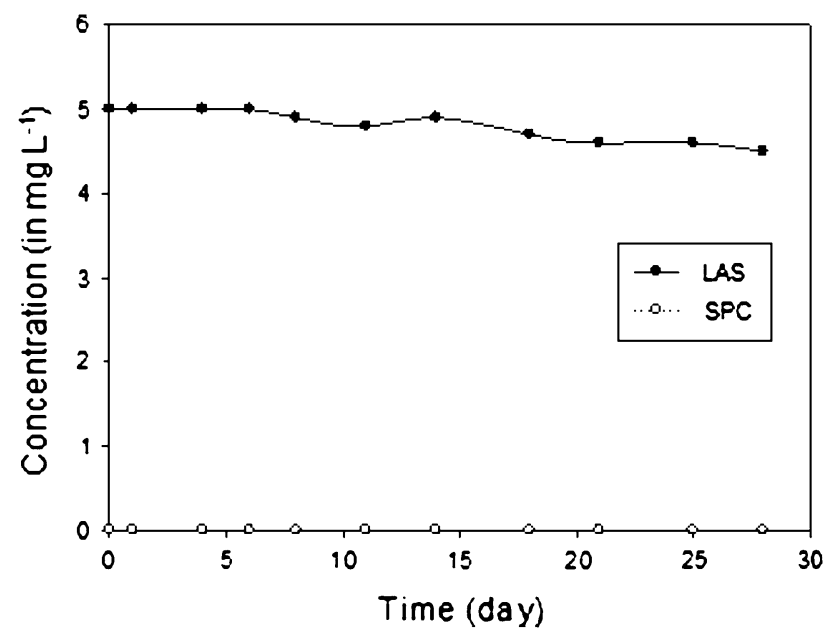

Fig. 6 LAS photodegradation under simulated solar light exposition

residues for cleaners and detergents in the environment; in addition, they have been proposed as molecular tracers for wastewater entering coastal marine environments wherever LABs are being used and released (Gustafsson et al. 2001). Because the concentrations of the total LAB are too low in surface water, a good environmental matrix to describe their accumulation point is the sediment. Another point of interest is their hydrophobicity (the $K_{\text {ow }}$ ranges from 7.45 to 8.19). LAB levels were determined in stations 2 and 4 (the Cortiou outfall). Using 1-phenylnonane as an internal standard, concentrations of total LABs in station 4 $\left(520 \mu \mathrm{g} \mathrm{kg}^{-1}\right)$ were observed as being four times higher than in station $2\left(120 \mu \mathrm{g} \mathrm{kg}^{-1}\right)$. This finding is in agreement with the LAS observation in this study. When compared to levels found in other areas, the concentrations of total LAB found in this study were rather low (Eganhouse and Sherblom, 2001; Bayona et al. 1986), ranging from 10 to $19,400 \mu \mathrm{g} \mathrm{kg}^{-1}$. Figure 7 shows four LAB homologs that were found in Cortiou sediments with 12 different resolved isomers. Accordingly, we observed a possible selective microbial degradation of the C9-C11 alkyl chain rather than the major homologs (C12). For instance, 7-C9-, 6-C9-, 5-C10-, 3-C10- and 4-C11-LABs were markedly degraded in station 2 (showed by arrow signs in Fig. 7). However, the predominance of $\mathrm{C}_{12}$-LAB in this study was in agreement with findings from previous studies $(\mathrm{Gu}-$ stafsson et al. 2001; Eganhouse and Sherblom 2001) of municipal WWTP discharge combined with sewer effluents

Fig. 7 A SIM fragmentogram from a tropillium ion $(\mathrm{m} /$ $z=91)$ of saturated hydrocarbon fractions; $\mathrm{n}$ and $\mathrm{m}$ indicate alkyl chain lengths on both sides of the LAB phenyl groups. Arrows indicate (bio)degraded isomers of LABs
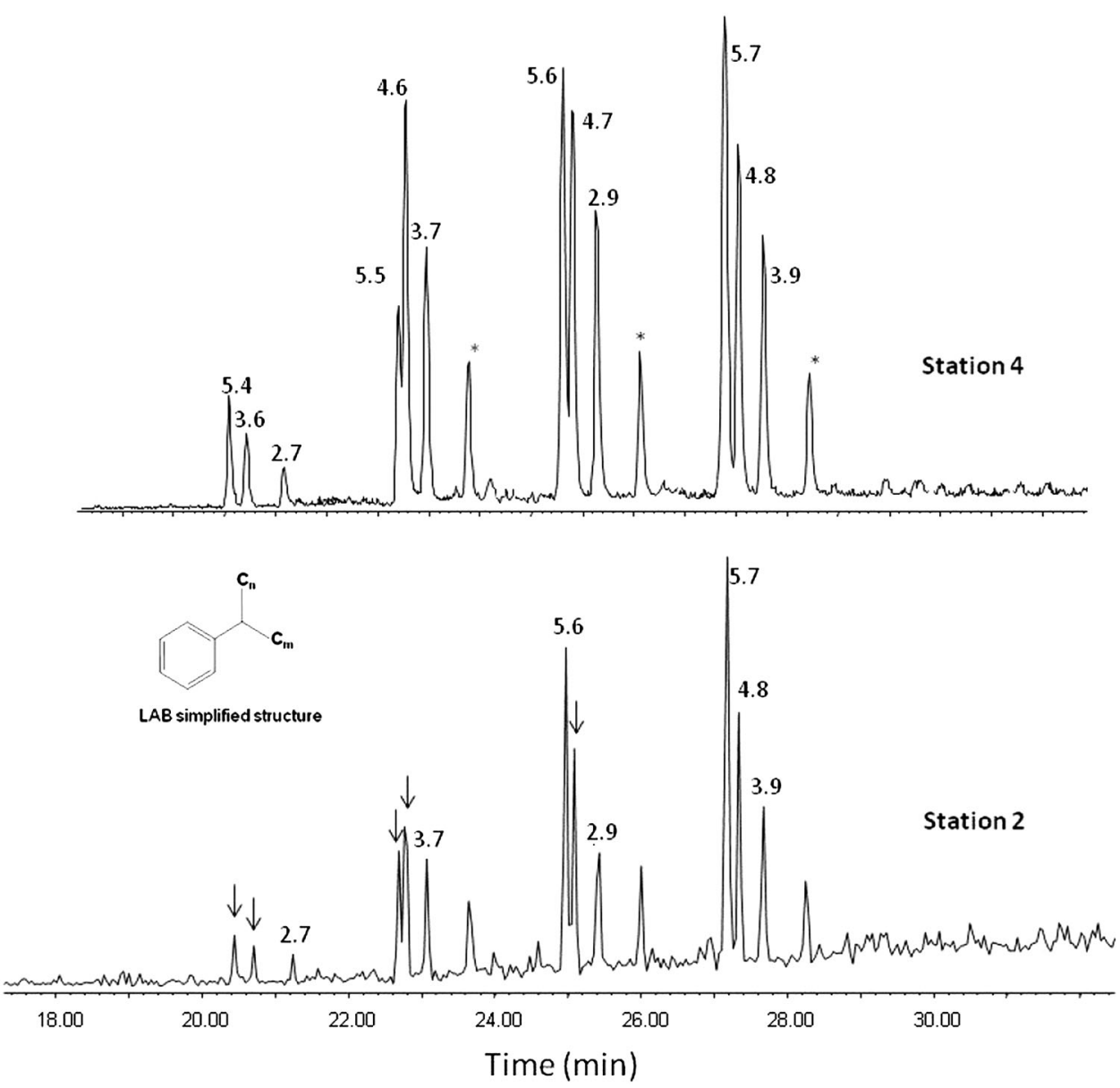
near Boston Harbor. A calculation of the ratios between the internal (I) and external (E) isomers of LABs as proposed by Bayona et al. (1986) show few differences ( 0.85 vs. 0.94 for station 2 and 4, respectively). This finding suggests that the biodegradation of LAS derivatives in sediments occurs to a lesser extent.

\section{Conclusion}

These results show the presence and persistence of LAS (mainly $\mathrm{C}_{10}-\mathrm{C}_{13}$ compounds) in the sea surface layer and at greater depths up to $3 \mathrm{~km}$ from the discharge point, whereas SPC $\left(\mathrm{C}_{4}-\mathrm{C}_{6}\right.$ compounds $)$ were only detected in the surface layer near the discharge point. The LAS therefore seem to be slowly degrading in the study area. An important result is their presence at concentrations that are three to four times higher in the surface layer than at a depth of $2 \mathrm{~m}$. NPEO were measured only in minor quantities, and no other metabolites (NP, NPEC) were detected.

The degradation of LAS under controlled conditions in natural seawater shows that photodegradation under annual average solar irradiation conditions in the south of France results in no appreciable drop in the LAS concentration. The results of our biodegradation experiments under natural marine conditions are in accordance with the results from other studies and show that LAS are quickly degraded to SPC and disappear after the first 20 days. The SPC are then slowly degraded, but no complete biodegradation was observed in our study. This finding was confirmed by the LAB analysis for stations 2 and 4. Moreover, this paper also suggests that laboratory biodegradation assays should be conducted by using regular substrate inputs to be closer to the natural conditions found in coastal environments and especially to better mimic the conditions found in marine sewage discharge areas.

Acknowledgments This research was supported by a grant from the Rhone-Mediterranean and Corsica Water Agency (Grant 2009-1316). This work was partially supported by ANR project MARSECO (ANR-CESA-018-06). We acknowledge Ms. Valentini-Poirier and Mr. Boissery for sparking our interest in this study.

\section{References}

Andreu V, Pico Y (2004) Determination of linear alkylbenzenesulfonates and their degradation products in soils by liquid chromatography-electrospray-ion trap multiple-stage mass spectrometry. Anal Chem 76:2878-2885

Bayona JM, Albaiges J, Solanas AM, Grifoll M (1986) Selective aerobic degradation of linear alkylbenzenes by pure microbial cultures. Chemosphere 15(5):595-598

Bellan G, Bourcier M, Salen-Picard C, Arnoux A, Casserley S (1999) Benthic ecosystem changes associated with wastewater treatment at marseille: implications for the protection and restoration of the Mediterranean coastal shelf ecosystems. Water Environ Res 71:483-493

Bester K, Theobald N, Schröder HF (2001) Nonylphenols, nonylphenol-ethoxylates, linear alkylbenzenesulfonates (LAS) and bis(4-chlorophenyl)-sulfone in the German Bight of the North Sea. Chemosphere 45(6-7):817-826

Boudenne JL, Coulomb B, Djellal L, Théraulaz F (2001) Determination of LAS in wastewater treatment plants: comparative study between conventional biodegradation testing and an alternative photo-oxidation method. Int J Environ Anal Chem 81(1):55-72

Castillo M, Riu J, Ventura F, Boleda R, Scheding R, Schröder HF, Nistor C, Emneus J, Eichhorn P, Knepper TP, Jonkers CCA, De Voogt P, Gonzalez-Mazo E, Leon VM, Barcelo D (2000) Interlaboratory comparison of liquid chromatographic techniques and enzyme-linked immunosorbent assay for the determination of surfactants in wastewaters. J Chromatogr A 889:195-199

Di Corcia A, Samperi R, Marcomini A (1994) Aromatic surfactants and biodegradation intermediates in sewage by solid-phase extraction and LC. Environ Sci Technol 28:850-858

Diaz A, Ventura F, Galceran MT (2002) Simultaneous determination of estrogenic short ethoxy chain nonylphenols and their acidic metabolites in water by an in-sample derivatization/solid phase microextraction method. Anal Chem 74:3869-3876

Ding WH, Tzing SH (1998) Analysis of nonylphenol polyethoxylates and their degradation products in river water and sewage effluent by gas chromatography-ion trap (tandem) mass spectrometry with electron impact and chemical ionization. J Chromatogr A 824:79-86

Eganhouse RP, Sherblom PM (2001) Anthropogenic organic contaminants in the effluent of a combined sewer overflow: impact on Boston Harbor. Mar Environ Res 51(1):51-74

European Committee of Surfactants and their Organic Intermediates (CESIO), Statistics, 2008 (http://www.cefic.be/files/publications/ cesio)

Fernandez J, Riu J, Garcia-Calvo E, Rodriguez A, Fernandez-Alba AR, Barcelo B (2004) Determination of photodegradation and ozonation by products of linear alkylbenzene sulfonates by liquid chromatography and ion chromatography under controlled laboratory experiments. Talanta 64(1):69-79

Gledhill W, Saeger VW, Treh ML (1991) An aquatic environmental safety assessment of linear alkylbenzene. Environ Toxicol Chem 10(2):169-178

Gonzalez S, Petrovic M, Barcelo D (2004) Simultaneous extraction and fate of linear alkylbenzene sulfonates, coconut diethanol amides, nonylphenol ethoxylates and their degradation products in wastewater treatment plants, receiving coastal waters and sediments in the Catalonian area (NE Spain). J Chromatogr A 1052(1-2):111-120

Gonzalez-Mazo E, Honing M, Barcelo D, Gomez-Parra A (1997) Monitoring long-chain intermediate products item the degradation of linear alkylbenzene sulfonates in the marine environment by solid-phase extraction followed by liquid chromatography/ ionspray mass spectrometry. Environ Sci Technol 31:504-510

Gustafsson O, Long CM, Macfarlane J, Gschwend PM (2001) Fate of Linear alkylbenzenes released to the coastal environment near Boston Harbor. Environ Sci Technol 35(10):2040-2048

Hampel M, Mreno-Garrido I, Sobrino C, Lubian LM, Blasco J (2001) Acute toxicity of LAS homologues in marine microalgae: esterase activity and inhibition growth as endpoints of toxicity. Ecotox Environ Saf 48(3):287-292

Houde F, DeBlois C, Berryman D (2002) Liquid chromatographictandem mass spectrometric determination of nonylphenol polyethoxylates and nonylphenol carboxylic acids in surface waters. J Chrom A 961:245-256

Jahnke A, Gandrass J, Ruck W (2004) Simultaneous determination of alkylphenol ethoxylates and their biotransformation products by 
liquid chromatography/electrospray ionisation tandem mass spectrometry. J Chrom A 1035:115-122

Jobling S, Sheahan D, Osborne JA, Matthiessen P, Sumpter JP (1996) Inhibition of testicular growth in rainbow trout (Oncorhynchus mykiss) exposed to estrogenic alkylphenolic chemicals. Environ Toxicol Chem 15:194-202

Jonkers N, Laane R, de Voogt P (2005) Sources and fate of nonylphenol ethoxylates and their metabolites in the Dutch coastal zone of the North Sea. Mar Chem 96(1-2):115-135

Koh YK, Chiu TY, Boobis AR, Cartmell E, Pollard SJT, Scrimshaw MD, Lester JN (2008) A sensitive and robust method for the determination of alkylphenol polyethoxylates and their carboxylic acids and their transformation in a trickling filter wastewater treatment plant. Chemosphere 73:551-556

Lara-Martin PA, Gomez-Parra A, Gonzalez-Mazo E (2008a) Reactivity and fate of synthetic surfactants in aquatic environments. Trends Anal Chem 27(8):684-695

Lara-Martin PA, Gomez-Parra A, Gonzalez-Mazo E (2008b) Sources, transport and reactivity of anionic and non-ionic surfactants in several aquatic ecosystems in SW Spain: a comparative study. Environ Pollut 156(1):36-45

Lara-Martin PA, Gomez-Parra A, Sanz JL, Gonzalez-Mazo E (2010) Anaerobic degradation pathway of linear alkylbenzene sulfonates (LAS) in sulfate-reducing marine sediments. Environ Sci Technol 44:1670-1676

Leon SM, Gonzalez-Mazo E, Gomez-Parra A (2000) Extraction and isolation of linear alkylbenzene sulfonates and their intermediate metabolites from various marine organisms. J Chromatogr A 889(1-2):99-104

Leon SM, Gomez-Parra A, Gonzalez-Mazo E (2004) Biodegradation of linear alkylbenzene sulfonates and their degradation intermediates in seawater. Environ Sci Technol 38(8):2359-2367

Marcomini A, Capri S, Giger W (1987) Determination of linear alkylbenzenesulphonates, alkylphenol polyethoxylates and nonylphenol in waste water by high-performance liquid chromatography after enrichment on octadecylsilica. J Chromatogr A 403:243-252

Marcomini A, Di Corcia A, Samperi R, Capri S (1993) Reversedphase high-performance liquid chromatographic determination of linear alkylbenzene sulphonates, nonylphenol polyethoxylates and their carboxylic biotransformation products. J Chromatogr A 644:59-61

Mungray AK, Kumar P (2009) Fate of linear alkylbenzene sulfonates in the environment: a review. Int Biodeter Biodegrad 63:981-987

Munoz I, Gomez-Ramos MJ, Aguera A, Fernandez-Alba AR, GarciaReyes JF, Molina-Diaz A (2009) Chemical evaluation of contaminants in wastewater effluents and the environmental risk of reusing effluents in agriculture Trends. Anal Chem 28(6):676-694
Nunez L, Turiel E, Tadeo JL (2007) Determination of nonylphenol and nonylphenol ethoxylates in environmental solid samples by ultrasonic-assisted extraction and high performance liquid chromatography-fluorescence detection. J Chromatogr A 1146:157-163

Perales JA, Manzano MA, Sales D, Quiroga JM (2003) Biodisposition of linear alkylbenzene sulphonates and their associated sulphophenyl carboxylic acid metabolites in sea water. Int Biodeter Biodegr 51:187-194

Petrovic M, Diaz A, Ventura F, Barcelo D (2001) Simultaneous determination of halogenated derivatives of alkylphenol ethoxylates and their metabolites in sludges, river sediments and surface, drinking, and wastewaters by liquid chromatographymass spectrometry. Anal Chem 73:5886-5895

Prats D, Lopez C, Vallejo D, Varo P, Leon VM (2006) Effect of temperature on the biodegradation of linear alkylbenzene sulfonate and alcohol ethoxylate. J Surf Deterg 9(1):69-75

Sarrazin L, Arnoux A, Rebouillon P (1997) High-performance liquid chromatographic analysis of a linear alkylbenzenesulfonate an dits environmental biodegradation metabolites. J Chromatogr A 760:285-291

Suri M, Huld TA, Dunlop ED, Ossenbrink HA (2007) Potential of solar electricity generation in the European Union member states and candidate countries. Sol Energy 81:1295-1305

Swisher RD (1987) Surfactant biodegradation. Marcel Dekker, New York

Takada H, Ogura N (1992) Removal of linear alkylbenzenesulfonates (LAS) in the Tamagawa estuary. Mar Chem 37:257-263

Tan X, Yim SY, Uppu P, Kleinow KM (2010) Enhanced bioaccumulation of dietary contaminants in catfish with exposure to the waterborne surfactant linear alkylbenzene sulfonate. Aquat Toxicol 99(2):300-308

Trehy ML, Gledhill WE, Orth RG (1990) Determination of linear alkylbenzenesulfonates and dialkyltetralinsulfonates in water and sediment by gas chromatography/mass spectrometry. Anal Chem 62:2581-2589

Tubau I, Vasquez-Sune E, Carrera J, Gonzalez S, Petrovic M, Lopez de Alda MJ, Barcelo D (2010) Occurrence and fate of alkylphenol polyethoxylate degradation products and linear alkylbenzene sulfonate surfactants in urban ground water: Barcelona case study. J Hydrol 383(1-2):102-110

US.EPA (1998) Fate, transport and transformation test guidelines. OPPTS 835. 3160: biodegradability in sea water. Washington, DC. http://fedbbs.access.gpo.gov/library/epa_835/835-3160.pdf, Jan 2013

Zgola-Grzeskowiak A, Grzeskowiak T, Rydlichowski R, Lukaszewski Z (2009) Determination of nonylphenol and short-chained nonylphenol ethoxylates in drain water from an agricultural area. Chemosphere 75:513-518 